\title{
DSPWM Multilevel Technique of 27-Levels based on FPGA for the Cascaded DC/AC Power Converter Operation
}

N. M. Salgado-Herrera ${ }^{1}$, Aurelio Medina-Ríos ${ }^{1}$, Roberto Tapia-Sánchez $^{1}$, Olimpo Anaya-Lara ${ }^{2}$ and J.R. Rodríguez-Rodríguez ${ }^{3}$.

1. Universidad Michoacana de San Nicolás de Hidalgo Facultad de Ingeniería Eléctrica, División de Estudios de Posgrado, Morelia, Michoacán, México, CP 58030.

2. Department of Electronic and Electrical Engineering, Institute for Energy and Environment, University of Strathclyde, Glasgow, G1 1XW, U.K.

3. National Autonomous University of Mexico (UNAM), Department of Electrical Energy, Mexico.

E-mails:nidia402@dep.fie.umich.mx,amedinr@gmail.com,rtsanchez@dep.fie.umich.mx, olimpo.anaya-lara@eee.strath.ac.uk,jr_386@hotmail.com.

Abstract - In this paper a Digital Sinusoidal Pulse Width Modulation (DSPWM) multilevel technique of 27-levels based on FPGA is introduced, as an alternative to control of the DC/AC multilevel power converters. The implementation of this technique with a Field Programmable Gate Array (FPGA) XC3S500E model is achieved in the Xilinx Spartan 3E-FPGA platforms. An experimental prototype is implemented by three-cascaded H-bridges controlled by the DSPWM multilevel technique, generating high efficiency, low cost and lower harmonic content. The efficiency of the DSPWM multilevel technique using R, RL, RC and RLC loads connected to the power network is verified.

Keywords—DSPWM, FPGA, multilevel H-bridges, cascaded DC/AC converters.

\section{INTRODUCTION}

Through the years, the research attention in the DC/AC multilevel power converters controlled by Pulse Width Modulation (PWM) has increased, in merit to identify technical advantages in the power quality problems solution [1]. Among the different types of multilevel topologies of the DC/AC power converters, three are considered, i.e. Diode-clamped, flying capacitor and cascaded H-bridge [2]. Then, when the multilevel signal implementation is required with a low harmonic content, the cascaded H-bridge topology is used. This topology appeared for the first time in 1975 [3] and this is mainly implemented because it is possible to generate a greater number of levels with a lesser number of switches and electronic components [4-5]. Subsequently, the Total Harmonic Content (THD) is lower among the number of levels 
containing a sinusoidal signal [6-7]. In addition, the series connection of multilevel power converters reduces the voltage stress of each switch in the H-bridge module, making DC/AC multilevel converters suitable for high power applications.

Several types of modulation methods have been proposed for multilevel converters based on two approaches, i.e. Pulse Width Modulation (PWM) and Vector Modulation (VM). The vector modulation method generates the converter commutation states from a reference vector, its implementation is more complex and it is more computationally demanding, as this technique requires the coding of $\mathrm{N}^{3}$ different voltage combinations for the output voltage generation of $\mathrm{N}$ levels [8]. The pulse width modulation is generated by the comparison of modulated and carrier signals. In the multilevel signal generation, several carriers are used; its advantage is the implementation simplicity and low computational cost, because to generate a multilevel signal of n-levels, it is only necessary the comparison between a modulated signal and n-1 carriers [9].

To achieve this aim, the $\mathrm{DC} / \mathrm{AC}$ multilevel converters control has been progressively migrated from analog to digital operation [10], i.e. the digital modulation techniques are quickly becoming the most generalized framework in modern power electronics applications. Digital Sinusoidal Pulse Width Modulation (DSPWM) is a modulation technique created by the internal generation of the modulated and carrier signals in a digital controller. Hence, different digital controllers, such as microprocessors, Digital Signal Processor (DSP), Application Specific Integrated Circuits (ASIC) and Field Programmable Gate Array (FPGA) are gaining importance in power electronics applications [11], as these allow the DSPWM to be implemented easily with advantages in terms of better performance, reduction of harmonic distortion and low cost of experimental prototypes. However, the operation of some digital controllers is linked to disadvantageous issues, e.g. the use of ASICs is sometimes an effective solution in applications designed for large markets, since its development cost is only justified by large volumes. In DSPs the execution time synchronization is complex and in microcontrollers the generation of multiple output signals is insufficient [12-13].

The importance of developing digital controllers in low-level programming devices (direct control over hardware), such as FPGAs, in the control of switching power converters, remains in the concurrency advantages (it allows the division of complex logical algorithms in a large number of small tasks, which are simultaneously solved) [14-17]; i.e. it is possible the control of multiple switches with high processing speed. This is ideal when a very high switching frequency and bandwidth are required. At the same time, the FPGA is dynamically and partially reconfigurable, a fact that can be exploited in order to reduce the total power consumption. The hardware re-configuration allows the constantly non-required functions to be stored in a low power memory and these with the predefined register in the FPGA are configured [18]. Besides, the VHDL (combination between VHSIC (Very High Speed Integrated Circuits) and HDL (Hardware Description Language)) is designed and optimized to describe the behavior of digital systems; which ranges from simple logic gates to custom chips [19]. When the VHDL language is combined with the characteristics of an FPGA as, concurrency and re-configuration, it allows 
feasible and efficient implementations of DSPWM control, in merit to its flexibility, versatility and simplicity properties [20].

The DSPWM multilevel technique can be applied in some research works, such as: In [21-23], research investigation on cascaded H-bridge multilevel converters of 27-levels controlled by DSPs is reported, thus generating a complex synchronization of execution time and an excess of unnecessary software, due to the DSP serial programming process. In [24], a DC/AC multilevel converter topology that gets all the additive and subtractive combinations of the input DC levels in a real-time simulator is proposed. However, the authors present the multilevel topology simulation generating of 9 and 27-levels, but only an experimental prototype to generate 9-levels is implemented; which is acceptable but not enough, since the control strategy to generate 27levels through the proposed topology is not detailed. In [25], the control of cascaded H-bridge in a photovoltaic system based on sinusoidal PWM techniques through an FPGA is reported. This is a potential application; however, the authors only report the system simulation. In [26], the control of a voltage source inverter with multilevel technique is performed using the Space Vector Pulse Width Modulation (SVPWM) technique in an FPGA; nevertheless, the authors generate only a 5-levels multilevel signal, which generates a higher Total Harmonic Distortion (THD) in the AC network. To reduce this THD, the number of levels in the output voltage must be increased; this results in an increase of unnecessary software.

In this paper, a DSPWM multilevel technique of 27-levels based on the Xilinx Spartan 3E FPGA platform (XC3S500E model) is implemented, as an alternative of control to a DC/AC multilevel power converter formed by three-cascaded H-bridges, for the THD reduction in different load types. The paper scope is enhanced with the incorporation of R, RL, RC and RLC loads in the power system. Through the parallel data processing of the FPGA architecture a good resolution, high efficiency, low harmonic content and low cost are acquired in the prototype implementation. The paper organization is as follows: in Section II, the technical implementation of the DSPWM multilevel signal of 27-levels is detailed; in Section III, the DSPWM multilevel signal simulation of 27-levels is presented; in Section IV, the results of the prototype implementation detailed in Section II are given and analyzed, and finally in Section IV, the main conclusions of this research work are drawn.

\section{Digital Sinusoidal Pulse Width Modulation (DSPWM) MultileVel Technique DESCRIPTION}

Different types of multilevel modulation methods are already well established. The Phase Shifted PWM (PSPWM), Phase Disposition PWM (PDPWM), Phase Opposition Disposition PWM (PODPWM) and Selective Harmonic Elimination PWM (SHEPWM) are some examples of sinusoidal Pulse Width Modulation methods. The PSPWM, PDOWM and PODPWM multilevel methods in the power converters controlled with high frequency switching are applied; The SHEPWM technique is applied in converters with very high power, controlled through low frequency switching algorithms [27-29]. In this paper, the DSPWM implementation is made based on the phase disposition method, since this modulation method achieves a lower THD with a higher number of voltage levels in the output signal, in comparison to the methods cited in [30]. 
The DSPWM generation signal is achieved through direct comparison of a sinusoidal reference signal (modulating signal) and a high frequency triangular signal (carrier signal).

The DSPWM multilevel generation is represented by the expression:

$$
n L=n-1
$$

where $n$ is the number of levels. The modulation index $m_{a}$ is generated from the carrier signal frequency $f_{c}$ and the modulating signal frequency $f_{m}$ is,

$$
m_{a}=\frac{f_{C}}{f_{m}}
$$

Its function is to reduce stress on the converter switching devices due to high power handling. This is achieved by properly executing the gating signals for the switches control. These modulation techniques need more computational capacity; this requirement is satisfied when the modulation technique in a FPGA is implemented.

\section{A. Modulated Signal Formation}

The modulation signal has a frequency of $60 \mathrm{~Hz}$; it is created by the data stored in ROM, corresponding to the sinusoidal signal peak-to-peak amplitude. This amount of data has been selected for high precision of the modulation signal. Table 3 shows the stored content in ROM.

An array of 500 locations in the ROM is selected from Table 1. The FPGA model XC3S500E operates at $50 \mathrm{MHz}$, since a sinusoidal modulation signal of $60 \mathrm{~Hz}$ is needed, then this frequency is decreased. The base modulation signal frequency $f_{B M S}$ is obtained as,

$$
f_{B M S}=\frac{f_{F P G A}}{f_{S M S}}
$$

where $f_{F P G A}$ is the frequency to operate the FPGA model XC3S500E and $f_{S M S}$ is the frequency of the sinusoidal modulation signal.

Finally, the 500 data store in ROM are assigned by the base modulation signal frequency as,

$$
f_{D S}=\frac{f_{B M S}}{500}
$$

where $f_{B M S}$ is the base modulation signal frequency and $f_{D S}$ is the frequency of stored data in ROM.

Table 2 shows the process to generate the base modulated signal frequency; this is achieved with $f_{D S}$ by using a counting process of 1666 clock cycles. Table 3 details the process followed to select the 500 ROM locations. In Table 4, the process of value assignation in the corresponding ROM locations to generate the sinusoidal signal is shown. The described tasks in Tables 2, 3 and 4 are simultaneously processed by the FPGA. The stored data in ROM are continuously assigned every 1666 clock cycles. Therefore, the advantages of simplicity, efficiency, versatility and flexibility are achieved. 


\section{B. Carrier Signals Formation}

Triangular carriers were synthesized using the master clock pulses of the FPGA, which may run at $50 \mathrm{MHz}$. The carrier signal frequency is 10 times higher than the modulating signal frequency; therefore, the signal carrier frequency $f_{S C}$ is obtained as,

$$
f_{S C}=\frac{f_{F P G A}}{\left(f_{D S}\right) * 10}
$$

where $f_{F P G A}$ is the frequency to operate the FPGA model XC3S500E and $f_{D S}$ is the 500 data stores in ROM.

Table 5 shows the process to generate the carrier signal base frequency by (4) and (5). By increasing its level to a maximum $T$ the main triangular waveform (carrier) is generated, and then decreasing it to zero following a stair pattern. This sequence is continuously repeated until the overall process stops, as shown in Table 6.

$$
\begin{aligned}
& \text { Carrier } \\
& \text { Carrier }+350 \rightarrow \text { Carrier }(1) \\
& \text { Carrier }+700 \rightarrow \text { Carrier }(2) \\
& \text { Carrier }+1050 \rightarrow \text { Carrier }(3) \\
& \cdot \\
& \cdot \\
& \cdot \\
& \text { Carrier }+8050 \rightarrow \text { Carrier }(24) \\
& \text { Carrier }+8400 \rightarrow \text { Carrier }(25) \\
& \text { Carrier }+8750 \rightarrow \text { Carrier }(26)
\end{aligned}
$$

To form each of the remaining triangular signals, an offset is added to the main triangular signal until reaching the peak value, as shown in (6). The modulating signal and the sum of $n$ carrier signals must have the same peak-to-peak amplitude. Finally, the sinusoidal modulation signal is continuously compared against each of the $n$ carrier signals, generating a train of on-tooff switching pulses. That is, if the reference is larger than $n$ carrier signals, then the pulse is active, but if the reference is smaller than $n$ carrier signals, then the pulse is turned off, i.e.:

$$
\begin{aligned}
& \text { Modulated }>\operatorname{Carrier}(n) \rightarrow D S P W M=1 \\
& \text { Modulated }<\operatorname{Carrier}(n) \rightarrow D S P W M=0
\end{aligned}
$$

The diagram of Figure 1 shows the generation of the DSPWM signals; these are required to control the twelve switches (IGBTs) of the DC/AC multilevel converter formed by the threecascaded H-bridges.

Figure 1 Generation of DSPWM multilevel signal 
The twelve switching signals are implemented in the FPGA (these signals come from the comparison of the modulated signal and the 26 carrier signals, as shown in Figure 1), due to the required combinational logic complexity for the correct turn on/off of the IGBTs corresponding to the $\mathrm{AC} / \mathrm{DC}$ multilevel converter.

\section{DSPWM MULTILEVEL Signal Simulation OF 27-LeVELS}

The Figure 2 shows the simulation of DSPWM multilevel signal of 27-levels. The control technique at the FPGA output has a maximum peak-to-peak voltage of $3.3 \mathrm{~V}$. The waveform simulation of Figure 2 is obtained with the Xilinx platform.

Figure 2 Simulation of DSPWM signal of 27-levels

Figure 3 shows the flow diagram that describes the DSPWM multilevel signal. It contains the described codes in Tables 1, 2, 3, 4, 5 and 6 .

Figure 3 Flow diagram of the DSPWM multilevel signal

\section{IMPLEMENTING THE DSPWM SIGNAL OF 27-LEVELS}

The main advantages linked to the construction of multilevel topologies are the generation of high-quality output voltages, the power increase, the THD mitigation and the reduction of voltage stress in power switching devices [31-33].

In this contribution, the DSPWM multilevel modulation technique is applied in the cascaded $\mathrm{H}$-bridge topology of Figure 4; its operating principle is explained through an H-bridge [34]. The H-bridge of Figure 4(a) consists of four switches $\mathrm{S}_{\mathrm{T} 1}, \mathrm{~S}_{\mathrm{T} 2}, \mathrm{~S}_{\mathrm{T} 3}$ and $\mathrm{S}_{\mathrm{T} 4}$. Switches $\mathrm{S}_{\mathrm{T} 1}$ and $\mathrm{S}_{\mathrm{T} 3}$ operate complementary to $\mathrm{S}_{\mathrm{T} 2}$ and $\mathrm{S}_{\mathrm{T} 4}$, producing three different output voltages through the switching control; the output voltages are $+\mathrm{V}_{\mathrm{DC}}, 0$ and $-\mathrm{V}_{\mathrm{DC}}$. In Figure $4(\mathrm{~b})$ the switches $\mathrm{S}_{\mathrm{T} 1}$ and $\mathrm{S}_{\mathrm{T} 3}$ are turned on to generate $+\mathrm{V}_{\mathrm{DC}}$. In Figure $4(\mathrm{c})$ switches $\mathrm{S}_{\mathrm{T} 2}$ and $\mathrm{S}_{\mathrm{T} 4}$ are turned on to produce $-\mathrm{V}_{\mathrm{DC}}$, and to generate $0 \mathrm{~V}$. Two options can be followed, i.e., switches $\mathrm{S}_{\mathrm{T} 1}$ and $\mathrm{S}_{\mathrm{T} 4}$ (Figure 4(d)) or $\mathrm{S}_{\mathrm{T} 2}$ and $\mathrm{S}_{\mathrm{T} 3}$ are turned on (Figure 4(e)). It is possible to choose any of these configurations without modifying the final waveforms. For this research work the configuration of Figure 4(e) is selected.

In order to obtain 27-levels in the DC/AC multilevel converter output using three-cascaded $\mathrm{H}$ bridges units, three different DC voltage sources are used, i.e. in the H-bridge 1 the DC voltage source 1 is nine times higher than the DC Voltage source 3 of the $\mathrm{H}$-bridge 3; and in the $\mathrm{H}$-bridge 2 the DC voltage source 2 is three times higher than the DC voltage source 3 of the H-bridge 3. The DSPWM implementation applied to the DC/AC multilevel converter is performed using a XC3S500E FPGA and VHDL.

Figure 4 Topological states of an H-bridge converter. a) H-bridge model; b) +VDC state; c) -

$$
\text { VDC state; d) } 0 \text { state; e) } 0 \text { state }
$$


Figure 5 Circuits corresponding to the used combinational logic of Table 8. a) Combinational logic of H-bridge 1; b) Combinational logic of $\mathrm{H}$-bridge 2; c) Combinational logic of $\mathrm{H}$-bridge 3

In Table 7 the turn on/off of each IGBT of the three-cascaded H-bridges are specified. The used combinational logic for the correct IGBTs switching is shown in Table 8. Figure 5 shows the circuits corresponding to the used combinational logic for the correct IGBT switching. Figure 5(a) shows the combinational logic to generate the train of pulses applied to the IGBTs of the Hbridge 1, Figure 5(b) illustrates the combinational logic applied to the IGBTs of the H-bridge 2 and Figure 5(c) shows the combinational logic for the IGBTs of the H-bridge 3.

Figure 6 Three-cascaded H-bridges configuration and equivalent circuit corresponding

Figure 6 shows the three-cascaded H-bridges configurations and the equivalent circuit corresponding to generate a multilevel output signal of 27-levels.

The general output of the DC/AC multilevel converter of Figure 6 is given by,

$$
\begin{gathered}
V_{\text {OUT }}=\left(S_{T 1}+3 S_{T 2}+9 S_{T 3}\right) V_{D C} \\
V_{\text {OUT }}=\square_{n=0}^{2}\left(3^{n}\right)\left(S_{T} * V_{D C}\right)
\end{gathered}
$$

where $S_{T}=\varepsilon\{-1,0,1\}, V_{D C}$ is the DC voltage and $V_{O U T}$ the DC/AC converter output voltage.

The DC/AC multilevel converters can generate a close to sinusoidal output voltage, depending on the number of signal voltage levels [35-36]. Figure 7(a) shows output voltage of the DC/AC multilevel converter of 27-levels (formed by three-cascade H-bridges). This is close to the sinusoidal waveform generated by a $312 \mathrm{~V}$ peak-to-peak voltage with a DC input voltage of $156 \mathrm{~V}$. Figure 7(b) shows a voltage zoom.

It is important to mention that, since the power electronic converter internally generates series parasite resistances, its output voltage varies with the connection of different types of loads, even if the voltage supply remains constant. In the proposed DC/AC multilevel converter, the series resistances depend on the filtered elements, the series impedance of the DC voltage supply and the conduction and switching losses of the semiconductor devices. For this case, an error of 3\% in the $\mathrm{I}^{2} \mathrm{R}$ losses is considered, due to the no load and full load variations, with efficiencies between $94 \%$ and $97 \%$ being generated.

Figure 7 The DSPWM output of 27-levels to single-phase unfiltered H-bridge DC/AC converter.

a) Total output voltage; b) Voltage zooms

The multilevel modulation technique functionality generated in the FPGA is verified and analyzed for the connection of different load types, i.e. R, RL, RC and RLC.

Figure 8 Types of loads tested in the DSPWM of 27-levels experimental prototype. a) R load; b) RL load; c) RC load; d) RLC or Second order load 
The Different types of load $\left(Z_{L O A D}\right)$ considered as impedances in the experimental prototype are shown in Figure 8. Table 9 gives the prototype and hardware data used in the experimental implementation.

In order to analyze the waveforms of the involved electric variables in the $\mathrm{DC} / \mathrm{AC}$ conversion by the multilevel converter, different connection nodes are selected between the 27-levels modulation process and the load.

Figure 9 Electric variables involved in the DC/AC energy conversion process. a) DSPWM pulse trains generated by FPGA; b) Voltages formed by the three-cascaded H-bridges; c) Voltage and current with $R$ load; d) Voltage and current with $R L$ load; e) Voltage and current with $R C$ load; f)

Voltage and current with $R L C$ load

Figure 9 shows the experimental results of the selected connection nodes. In particular, in Figure 9(a) the three DSPWM pulse trains: i.e. $S_{T 11}$ (yellow), $S_{T 21}$ (cyan), and $S_{T 31}$ (pink), generated by FPGA (corresponding to the first IGBT of each of the three-cascaded H-Bridge) are shown. Figure 9(b) illustrates the behavior of $V_{T 1}$ (yellow), $V_{T 2}$ (cyan) and $V_{T 3}$ (pink) voltages formed by the H-bridge converters. Please notice the generation of three voltage levels. Besides, the changes in topological states are inversely proportional to DC voltage of each $\mathrm{H}$-Bridge converter. The response of the total output voltage and the load current (yellow and cyan, respectively) for different loads are given in Figures 9(c), 9(d) and 9(e), generated by the R, RL and RC loads, respectively. In these Figures, the converter capacity to work with currents between quadrants of resistive, inductive and capacitive loads for different values of magnitude and phase, and without altering the operation and process of the output voltage $\left(V_{O U T}\right)$ is verified. Finally, Figure 9(f) shows the waveforms of a RLC load. It can be observed that the resistive element is supplied with a purely sinusoidal voltage waveform (pink), due to the recovery of the generated fundamental voltage. The THD of the output voltage is $3.06 \%$. The THD of the output current for each load is listed in Table 10. It is important to remark that in practice the resistors (Lab-Volt modules) are built of copper wire, and these have a parasite inductance, which slightly attenuates the measured THD; hence, it is not possible to obtain a completely resistive effect.

The Figure 10 shows the experimental prototype developed to apply the DSPWM multilevel technique of 27-levels with the FPGA. The main stages of implementation are highlighted in rectangles. It shows a $R L C$ load (Figure 10(a)); the pulse trains generated by the FPGA (Figure 10(b)); a supply $156 \mathrm{~V}$ DC voltage consisting on three different DC voltage sources, i.e. a DC voltage 3 of $12 \mathrm{~V}$ (Figure $10(\mathrm{c})$ ), a DC voltage 2 of $36 \mathrm{~V}$ (Figure $10(\mathrm{~d})$ ) and a DC voltage 1 of $108 \mathrm{~V}$ (Figure 10(e)); a FPGA device (Figure 10(f)); and a DC/AC converter made with threecascaded H-bridges (Figure (10g)); generating the AC multilevel output voltage of 27-levels, which produces the filtered waveform of Figure 9(f).

Figure 10 Prototype used to apply the DSPWM multilevel control technique of 27-levels. a) RLC load; b) DSPWM pulse trains generated by the FPGA; c) DC source voltage $3\left(V_{D C}\right)$; d) DC source voltage $2\left(3 V_{D C}\right)$; e) DC source voltage $1\left(9 V_{D C}\right)$; f) XC3S500E FPGA device; g) H-bridge converters 


\section{Conclusions}

In this contribution has been proposed a DSPWM multilevel technique of 27-levels using an FPGA model XC3S500E to control a DC/AC multilevel converter formed by three-cascaded Hbridges for the THD reduction in different load types. Its dynamic response with the implemented prototype in laboratory has been successfully verified.

It has been shown that with the characteristics of an FPGA (parallel data processing, reprogrammability and concurrency) in conjunction with the VHDL language, it is possible the generation of n-levels signals in multilevel applications, in merit to its flexibility, versatility and simplicity properties without excess of unnecessary software.

The multilevel modulation technique functionality generated in the FPGA has been verified and analyzed with the connection of different actual loads types, such as R, RL, RC y RLC, respectively. This allowed attesting the converter capacity to work with currents within quadrants of resistive, inductive and capacitive loads for different values of magnitude and phase, without altering the operation and process of the output voltage (VOUT).

It has been shown that a DSPWM multilevel signal with a high number of levels generates a higher quality quasi-sinusoidal output signal, with significantly less switching losses in the power converters. This has been tested and verified; i.e. the registered THD with the application of the proposed prototype was $3.06 \%$.

\section{REFERENCES}

[1] Cossutta P, Aguirre MP, Cao A, Raffo S, Valla MI. Single-Stage Fuel Cell to Grid Interface With Multilevel Current-Source Inverters, in IEEE Transactions on Industrial Electronics, vol. 62, no. 8, pp. 5256-5264, Aug. 2015.

[2] Feel-Soon Kang, Sung-Jun Park, Man-Hyung Lee, Cheul-U Kim. An efficient multilevelsynthesis approach and its application to a 27-level inverter, Industrial Electronics, IEEE Transactions on, vol.52, no.6, pp.1600, 1606, Dec. 2005.

[3] Baker RH, Bannister LH. Electric power converter, U.S. Patent 3867 643, Feb. 18, 1975.

[4] Antunes VME, Pires VF, Silva JFA. Narrow Pulse Elimination PWM for Multilevel Digital Audio Power Amplifiers Using Two Cascaded H-Bridges as a Nine- Level Converter, in IEEE Transactions on Power Electronics, vol. 22, no. 2, pp. 425- 434, March 2007.

[5] Vazquez S, Leon JI, Franquelo LG, Padilla JJ, Carrasco JM. DC-Voltage- Ratio Control Strategy for Multilevel Cascaded Converters Fed With a Single DC Source, in IEEE Transactions on Industrial Electronics, vol. 56, no. 7, pp. 2513-2521, July 2009.

[6] Yousefpoor N, Fathi SH, Farokhnia N, Abyaneh HA. THD Minimization Applied Directly on the Line-to-Line Voltage of Multilevel Inverters, in IEEE Transactions on Industrial Electronics, vol. 59, no. 1, pp. 373-380, Jan. 2012. 
[7] Palanivel P, Dash SS. Analysis of THD and output voltage performance for cascaded multilevel inverter using carrier pulse width modulation techniques, in IET Power Electronics, vol. 4, no. 8, pp. 951-958, September 2011.

[8] Zorig A, Barkat S, Belkheiri M, Rabhi A, Blaabjerg F. Novel Differential Current Control Strategy Based on a Modified Three-Level SVPWM for two Parallel-Connected Inverters, in IEEE Journal of Emerging and Selected Topics in Power Electronics, vol.PP, no.99, pp.1-1, June 2017.

[9] Lamb J, Mirafzal B. An Adaptive SPWM Technique for Cascaded Multilevel Converters With Time-Variant DC Sources, in IEEE Transactions on Industry Applications, vol. 52, no. 5, pp. 4146-4155, Sept.-Oct. 2016.

[10] Lupon E, Busquets-Monge S, Nicolas-Apruzzese J. FPGA Implementation of a PWM for a Three-Phase DC-AC Multilevel Active-Clamped Converter, Industrial Informatics, IEEE Transactions on, vol.10, no.2, pp.1296, 1306, May 2014.

[11] Navarro D, Lucı'a Ó, Barragán LA, Urriza I, Jiménez Ó. High-Level Synthesis for Accelerating the FPGA Implementation of Computationally Demanding Control Algorithms for Power Converters, in IEEE Transactions on Industrial Informatics, vol. 9, no. 3, pp. 1371-1379, Aug. 2013.

[12] Yuan FL, Wang CC, Yu TH, Marković D. A Multi-Granularity FPGA With Hierarchical Interconnects for Efficient and Flexible Mobile Computing, in IEEE Journal of Solid-State Circuits, vol. 50, no. 1, pp. 137-149, Jan. 2015.

[13] Windh S, et al. High-Level Language Tools for Reconfigurable Computing, in Proceedings of the IEEE, vol. 103, no. 3, pp. 390-408, March 2015.

[14] De Castro A, Zumel P, Garcia O, Riesgo T, Uceda J. Concurrent and simple digital controller of an DC/AC converter with power factor correction based on an FPGA, Power Electronics, IEEE Transactions on, vol.18, no.1, pp. 334- 343, Jan 2003.

[15] Foster I. Designing and Building Parallel Programs, Addison Wesley 1994.

[16] Naouar MW, Monmasson EA, Naassani A, Slama-Belkhodja I, Patin N. FPGA-based current controllers for ac machine drives-A review, IEEE Transactions, Ind. Electron., vol. 54, no. 4, pp. 1907-1925, Aug. 2007.

[17] Rodríguez-Andina JJ, Moure MJ, Valdes MD. Features, Design Tools, and Application Domains of FPGAs, IEEE Transaction. Ind. Electron, vol. 54, no. 4, pp. 1810-1823, August 2007.

[18] Paulsson K, Hubner M, Becker J. Cost-and Power Optimized FPGA based System Integration: Methodologies and Integration of a Low-Power Capacity-based Measurement Application on Xilinx FPGAs, Design, Automation and Test in Europe, 2008. DATE '08, vol., no., pp.50-55, 10-14 March 2008. 
[19] Shahdad, Lipsett, Marschner, Sheehan, Cohen. VHSIC Hardware Description Language, in Computer, vol. 18, no. 2, pp. 94-103, Feb. 1985.

[20] Selvamuthukumaran R, Gupta R. Rapid prototyping of power electronics converters for photovoltaic system application using Xilinx System Generator, in IET Power Electronics, vol. 7, no. 9, pp. 2269-2278, September 2014.

[21] Rotella M, Penailillo G, Pereda J, Dixon J. PWM Method to Eliminate Power Sources in a Nonredundant 27-Level Inverter for Machine Drive Applications, IEEE Trans. on Ind. Electron., Jan. 2009.

[22] Flores P, Dixon J, Ortuzar M, Carmi R, Barriuso P, Moran L. Static Var Compensator and Active Power Filter With Power Injection Capability, Using 27-Level Inverters and Photovoltaic Cells, IEEE Trans. on Ind. Electron., Jan. 2009.

[23] Dixon J, Breton AA, Rios FE, Rodriguez J, Pontt J, Perez MA. High-Power Machine Drive, Using Nonredundant 27-Level Inverters and Active Front End Rectifiers, IEEE Tran. On Pow. Electron., Nov. 2007.

[24] Krishna Kumar Gupta, Shailendra Jain. A multilevel Voltage Source Inverter (VSI) to maximize the number of levels in output waveform, International Journal of Electrical Power \& Energy Systems, Volume 44, Issue 1, January 2013, Pages 25-36, ISSN 01420615.

[25] Raveendhra D, Prakash P, Saini P. Simulation based analysis of FPGA controlled Cascaded H-Bridge Multilevel inverter fed solar PV system, Energy Efficient Technologies for Sustainability (ICEETS), 2013 International Conference on, pp. 568, 572, 10-12, April 2013.

[26] Renukadevi G, Rajambal K. Field programmable gate array implementation of space-vector pulse-width modulation technique for five-phase voltage source inverter, in IET Power Electronics, vol. 7, no. 2, pp. 376-389, February 2014.

[27] Wahidah Abd. Halim†े, Nasrudin Abd. Rahim, and Maaspaliza AzriSelective, "Harmonic Elimination for a Single-Phase 13-level TCHB Based Cascaded Multilevel Inverter Using FPGA," Journal of Power Electronics, Vol. 14, No. 3, pp. 488-498, May 2014.

[28] T. Atalik et al., "Multi-DSP and -FPGA-Based Fully Digital Control System for Cascaded Multilevel Converters Used in FACTS Applications," in IEEE Transactions on Industrial Informatics, vol. 8, no. 3, pp. 511-527, Aug. 2012.

[29] J. Han et al., "FPGA based hybrid cascade multilevel converter," 2009 IEEE International Symposium on Industrial Electronics, Seoul, 2009, pp. 494-498.

[30] Mircea Eremia, Chen-Ching Liu, Abdel-Aty Edris. VSC-HVDC Transmission, in Advanced Solutions in Power Systems:HVDC, FACTS, and Artificial Intelligence, 1, Wiley-IEEE Press, 2016, pp.163-165. 
[31] Salgado-Herrera NM, Medina-Rios A, Ramos-Paz A, Rodriguez-Rodriguez JR. Generation of a multilevel SPWM technique of 3,9 and 21 levels with FPGAs, in North American Power Symposium (NAPS), 2013, pp.1-5, 22-24, Sept. 2013.

[32] Vazquez G, Martinez-Rodriguez PR, Escobar G, Sosa JM, Martinez-Mendez R. (2016) A PWM method for single-phase cascade multilevel inverters to reduce leakage ground current in transformerless PV systems. Int. Trans. Electr. Energ. Syst.

[33] Nademi H, Das A, Norum L. (2014), An analysis of improved current control strategy for DC-AC modular multilevel converters. Int. Trans. Electr. Energ. Syst., 24: 976-991.

[34] Hu P, Jiang D, Zhou Y, Guo J, Lin Z, Liang Y. (2014), Modulation and control of a new alternate arm multilevel converter for high-voltage direct current system with direct current fault ride-through capability. Int. Trans. Electr. Energ. Syst., 24: 1017-1033.

[35] Babaei Ebrahim, Ali Dehqan, Mehran Sabahi. A new topology for multilevel inverter considering its optimal structures, Electric Power Systems Research, Volume 103, October 2013, Pages 145-156.

[36] Babaei Ebrahim, Farhadi Kangarlu Mohammad, Sabahi Mehran, Reza Alizadeh, Pahlavani Mohammad. Cascaded multilevel inverter using sub-multilevel cells, Electric Power Systems Research, Volume 96, March 2013, Pages 101-110, ISSN 0378-7796.

\section{TABLES}

Table 1 Modulation signal storage in ROM

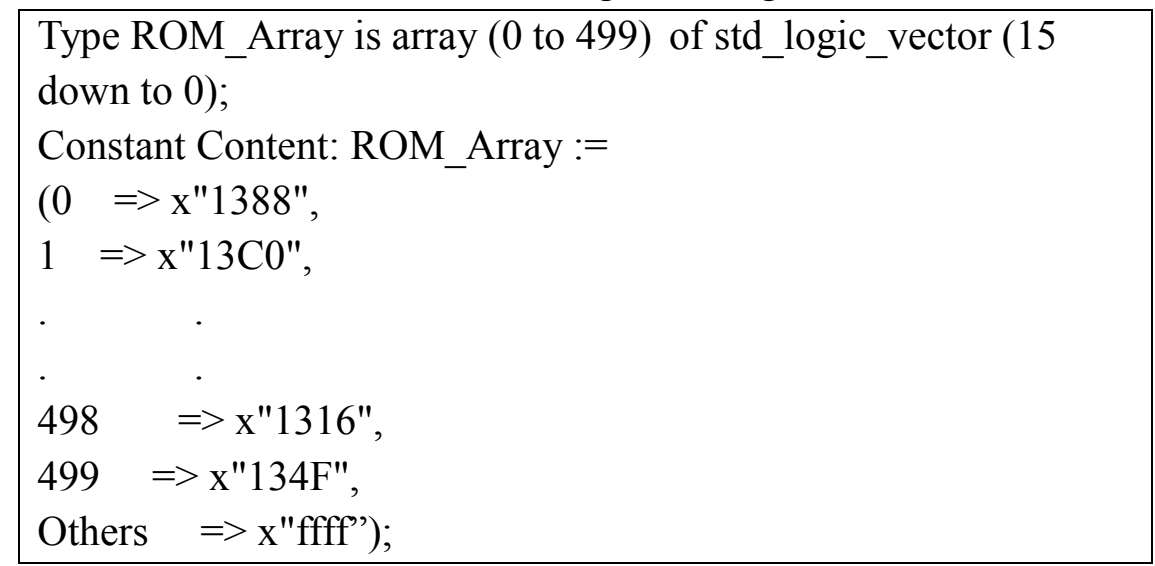

Table 2 Modulation signal at $60 \mathrm{~Hz}$.

Modulation: process $(\mathrm{clk}, \mathrm{clr})$
begin
if clr $=$ ' 1 ' then
Modulation_Signal $<=($ others $=>$ ' 0 ');
elsif clk'event and clk $=$ ' 1 ' then




if Modulation_Signal $=1666$
Modulation_Signal $<=($ others $=>$ ' 0 ' $)$
else
Modulation_Signal $<=$ Modulation_Signal $+1 ;$
end if;
end if;
end process Modulation;

Table 3 Location selection process in ROM.

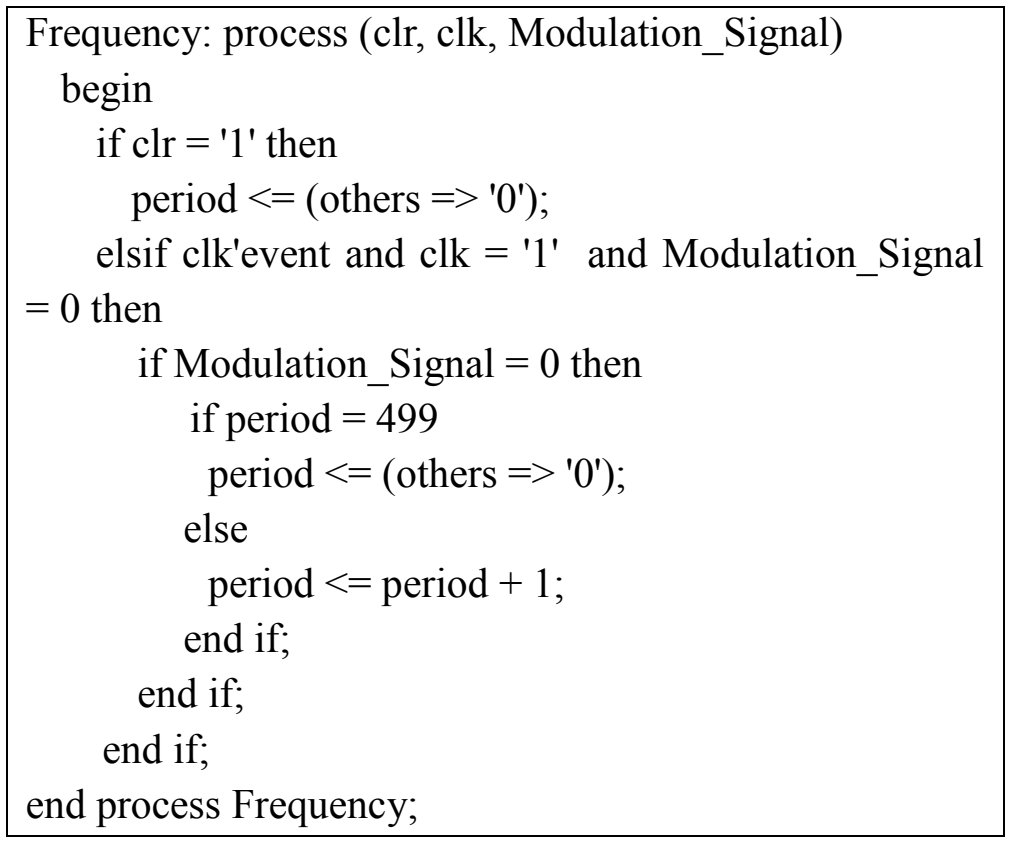

Table 4 Location value assignment in ROM

Assignation: process (Read, period)
begin
if (reset $=$ '' 1 ') then
Data_out $<=$ "ZZZZZZZ";
elsif (reset = '0') then
if ( $($ Read $=$ ' 1 ') then
Data_out $<=$ Content (conv_integer
(period)); else
end if;
end if; $\quad$ Data out $<=$ "ZZZZZZ";
end process Assignation;


Table 5 Carrier signal frequency process

Carrier1: process (clk, clr)
begin
if clr $=$ ' 1 ' then
Carrier_signal_frequency $<=($ others $=>$ ' 0 ');
elsif clk'event and clk $=$ ' 1 ' then
$\quad$ if Carrier_signal_frecuency $=2999$ then
$\quad$ Carrier_signal_frecuency $<=($ others $=>$ ' 0 ');
else
$\quad$ Carrier_signal_frecuency $<=$
Carrier_signal_frecuency +1 ;
end if;
end if;
end process Carrier1;

Table 6 Carrier signal creation process

Triangular: process (clr, clk, Carrier_signal_frequency)
begin
if clr $=$ ' 1 ' then
Carrier $<=($ others $=>$ ' 0 ');
elsif clk'event and clk $=$ ' 1 ' then
if Carrier_signal_frequency $<1500$ then
Carrier $<=$ Carrier +1 ;
else
Carrier $<=$ Carrier $-1 ;$
end if;
end if;
end process Triangular;


Table 7 Combination of witches in the DC/AC converter using three-cascaded H-bridges

\begin{tabular}{|c|c|c|c|c|c|c|c|c|c|c|c|c|c|c|c|}
\hline $\begin{array}{c}\text { Level } \\
\text { Number }\end{array}$ & & $V_{D}$ & & & $\begin{array}{l}\text { H-br } \\
\text { DC }=\end{array}$ & $\begin{array}{l}\text { dge } \\
\text { ST11S }_{\text {The }}\end{array}$ & & & $\begin{array}{l}\text { H-br } \\
0=S\end{array}$ & $\begin{array}{l}\text { dge } \\
{ }_{22} \mathrm{~S}_{\mathrm{T}}\end{array}$ & & & $\begin{array}{l}\text { H-br } \\
\text { DC }=\end{array}$ & $\begin{array}{l}\text { idge } 3 \\
S_{T 32} S\end{array}$ & \\
\hline & 9 & 3 & 1 & $S_{T 11}$ & $S_{T 12}$ & $S_{T 13}$ & $S_{T 14}$ & $S_{T 21}$ & $S_{T 22}$ & $S_{T 23}$ & $S_{T 24}$ & $S_{T 31}$ & $S_{T 32}$ & $S_{T 33}$ & $S_{T 34}$ \\
\hline 13 & 1 & 1 & 1 & 1 & 0 & 1 & 0 & 1 & 0 & 1 & 0 & 1 & 0 & 1 & 0 \\
\hline 12 & 1 & 1 & 0 & 1 & 0 & 1 & 0 & 1 & 0 & 1 & 0 & 0 & 1 & 1 & 0 \\
\hline 11 & 1 & 1 & -1 & 1 & 0 & 1 & 0 & 1 & 0 & 1 & 0 & 0 & 1 & 0 & 1 \\
\hline 10 & 1 & 0 & 1 & 1 & 0 & 1 & 0 & 0 & 1 & 1 & 0 & 1 & 0 & 1 & 0 \\
\hline 9 & 1 & 0 & 0 & 1 & 0 & 1 & 0 & 0 & 1 & 1 & 0 & 0 & 1 & 1 & 0 \\
\hline 8 & 1 & 0 & -1 & 1 & 0 & 1 & 0 & 0 & 1 & 1 & 0 & 0 & 1 & 0 & 1 \\
\hline 7 & 1 & -1 & 1 & 1 & 0 & 1 & 0 & 0 & 1 & 0 & 1 & 1 & 0 & 1 & 0 \\
\hline 6 & 1 & -1 & 0 & 1 & 0 & 1 & 0 & 0 & 1 & 0 & 1 & 0 & 1 & 1 & 0 \\
\hline 5 & 1 & -1 & -1 & 1 & 0 & 1 & 0 & 0 & 1 & 0 & 1 & 0 & 1 & 0 & 1 \\
\hline 4 & 0 & 1 & 1 & 0 & 1 & 1 & 0 & 1 & 0 & 1 & 0 & 1 & 0 & 1 & 0 \\
\hline 3 & 0 & 1 & 0 & 0 & 1 & 1 & 0 & 1 & 0 & 1 & 0 & 0 & 1 & 1 & 0 \\
\hline 2 & 0 & 1 & -1 & 0 & 1 & 1 & 0 & 1 & 0 & 1 & 0 & 0 & 1 & 0 & 1 \\
\hline 1 & 0 & 0 & 1 & 0 & 1 & 1 & 0 & 0 & 1 & 1 & 0 & 1 & 0 & 1 & 0 \\
\hline 0 & 0 & 0 & 0 & 0 & 1 & 1 & 0 & 0 & 1 & 1 & 0 & 0 & 1 & 1 & 0 \\
\hline-1 & 0 & 0 & -1 & 0 & 1 & 1 & 0 & 0 & 1 & 1 & 0 & 0 & 1 & 0 & 1 \\
\hline-2 & 0 & -1 & 1 & 0 & 1 & 1 & 0 & 0 & 1 & 0 & 1 & 1 & 0 & 1 & 0 \\
\hline-3 & 0 & -1 & 0 & 0 & 1 & 1 & 0 & 0 & 1 & 0 & 1 & 0 & 1 & 1 & 0 \\
\hline-4 & 0 & -1 & -1 & 0 & 1 & 1 & 0 & 0 & 1 & 0 & 1 & 0 & 1 & 0 & 1 \\
\hline-5 & -1 & 1 & 1 & 0 & 1 & 0 & 1 & 1 & 0 & 1 & 0 & 1 & 0 & 1 & 0 \\
\hline-6 & -1 & 1 & 0 & 0 & 1 & 0 & 1 & 1 & 0 & 1 & 0 & 0 & 1 & 1 & 0 \\
\hline-7 & -1 & 1 & -1 & 0 & 1 & 0 & 1 & 1 & 0 & 1 & 0 & 0 & 1 & 0 & 1 \\
\hline-8 & -1 & 0 & 1 & 0 & 1 & 0 & 1 & 0 & 1 & 1 & 0 & 1 & 0 & 1 & 0 \\
\hline-9 & -1 & 0 & 0 & 0 & 1 & 0 & 1 & 0 & 1 & 1 & 0 & 0 & 1 & 1 & 0 \\
\hline-10 & -1 & 0 & -1 & 0 & 1 & 0 & 1 & 0 & 1 & 1 & 0 & 0 & 1 & 0 & 1 \\
\hline-11 & -1 & -1 & 1 & 0 & 1 & 0 & 1 & 0 & 1 & 0 & 1 & 1 & 0 & 1 & 0 \\
\hline-12 & -1 & -1 & 0 & 0 & 1 & 0 & 1 & 0 & 1 & 0 & 1 & 0 & 1 & 1 & 0 \\
\hline-13 & -1 & -1 & -1 & 0 & 1 & 0 & 1 & 0 & 1 & 0 & 1 & 0 & 1 & 0 & 1 \\
\hline
\end{tabular}


Table 8. Combinational logic corresponding to each IGBT of cascaded H-bridges.

\begin{tabular}{|c|c|}
\hline $\begin{array}{c}\text { Switch } \\
\text { number }\end{array}$ & Corresponding Combinational Logic \\
\hline$\overline{S_{T 11}}$ & (DSPWM18) \\
\hline$\overline{S_{T 12}}$ & $\operatorname{NOT}\left(\mathrm{S}_{\mathrm{T} 11}\right)$ \\
\hline$\overline{S_{T 13}}$ & NOT (DSPWM9) \\
\hline$S_{T 14}$ & $\operatorname{NOT}\left(\mathrm{S}_{\mathrm{T} 13}\right)$ \\
\hline$S_{T 21}$ & $\begin{array}{l}\text { [(DSPWM24)] OR [(NOT(DSPWM18)) AND (DSPWM15)] OR } \\
\text { [(DSPWM9) AND (NOT(DSPWM6))] }\end{array}$ \\
\hline$\overline{S_{T 22}}$ & $\operatorname{NOT}\left(\mathrm{S}_{\mathrm{T} 21}\right)$ \\
\hline$\overline{S_{T 23}}$ & $\begin{array}{l}\text { [(DSPWM21)] OR [(NOT(DSPWM18)) AND (NOT(DSPWM12))] OR } \\
\text { [(DSPWM9) AND (NOT(DSPWM3))] }\end{array}$ \\
\hline$S_{T 24}$ & $\operatorname{NOT}\left(\mathrm{S}_{\mathrm{T} 23}\right)$ \\
\hline$S_{T 31}$ & $\begin{array}{l}\text { [(DSPWM26)] OR [(NOT(DSPWM24)) AND (DSPWM23)] OR } \\
\text { [(NOT(DSPWM21)) AND (DSPWM20)] OR [(NOT(DSPWM18)) AND (DSPWM17)] } \\
\text { OR [(NOT(DSPWM15)) AND (DSPWM14)] OR } \\
\text { [(DSPWM12) AND (NOT(DSPWM11))] OR [(DSPWM9) AND (NOT(DSPWM8))] } \\
\text { OR [(DSPWM6) AND (NOT(DSPWM5))] OR [(DSPWM3) AND (NOT(DSPWM2))] }\end{array}$ \\
\hline$\overline{S_{T 32}}$ & $\operatorname{NOT}\left(\mathrm{S}_{\mathrm{T} 31}\right)$ \\
\hline $\boldsymbol{S}_{T 33}$ & $\begin{array}{l}\text { [(DSPWM25)] OR [(NOT(DSPWM24)) AND (DSPWM22)] OR } \\
\text { [(NOT(DSPWM21)) AND (DSPWM19)] OR [(NOT(DSPWM18)) AND (DSPWM16)] } \\
\text { OR [(NOT(DSPWM15)) AND (NOT(DSPWM13))] OR } \\
\text { [(DSPWM12) AND (NOT(DSPWM10))] OR [(DSPWM9) AND (NOT(DSPWM7))] } \\
\text { OR [(DSPWM6) AND (NOT(DSPWM4))] OR [(DSPWM3) AND (NOT(DSPWM1))] }\end{array}$ \\
\hline$\overline{S_{T 34}}$ & $\operatorname{NOT}\left(\mathrm{S}_{\mathrm{T} 33}\right)$ \\
\hline
\end{tabular}

Table 9 Prototype and hardware values.

\begin{tabular}{|c|c|c|}
\hline \multicolumn{2}{|c|}{ Converter power } & $400 \mathrm{~W}$ \\
\hline \multicolumn{2}{|c|}{ Vout } & $110 \mathrm{~V}_{\mathrm{RMS}}$ \\
\hline \multicolumn{2}{|c|}{ THD (V } & $3.06 \%$ \\
\hline \multirow{3}{*}{$\begin{array}{c}\text { DC } \\
\text { Voltage } \\
\text { Sources }\end{array}$} & $V D C 1$ & $12 \mathrm{v}$ \\
\hline & $V D C 2$ & $36 \mathrm{v}$ \\
\hline & $V D C 3$ & $108 \mathrm{v}$ \\
\hline \multirow{4}{*}{$\begin{array}{c}\text { Types of } \\
\text { Load }\end{array}$} & $R$ & 20 \\
\hline & $R L$ & $\mathrm{R}=20 \Omega \mathrm{XL}=20 \Omega$ \\
\hline & $R C$ & $\mathrm{R}=20 \Omega \mathrm{XC}=20 \Omega$ \\
\hline & $R L C$ & $\begin{array}{c}\mathrm{R}=30 \Omega \mathrm{XL}=12.3 \Omega \\
\mathrm{XC}=240 \Omega\end{array}$ \\
\hline \multicolumn{2}{|c|}{ IGBT } & G4PC40UD-E \\
\hline \multicolumn{2}{|c|}{ FPGA } & XC3S500E model \\
\hline
\end{tabular}


Table 10 THD of current in different loads

\begin{tabular}{|c|c|}
\hline Load Types & Current THD (\%) \\
\hline R & 3.06 \\
\hline RL & 0.59 \\
\hline RC & 4.27 \\
\hline Second order or RLC & 0.63 \\
\hline
\end{tabular}

\section{BIOGRAPHY}

Nadia Maria Salgado-Herrera received her Ph.D. degree in Electrical Engineering from Universidad Michoacana de San Nicolás de Hidalgo (UMSNH) in 2016, the BSc. and M.S. degree in Electronics Engineering and Electrical Engineering from Instituto Tecnológico de Morelia, Michoacán, México, in 2009 and 2011, respectively. She is currently teaching in the Facultad de Ingeniería Eléctrica at the UMSNH. Her research areas include Power electronics, Power Quality and Renewable energy.

J. Aurelio Medina-Rios Obtained his Ph.D. from the University of Canterbury, Christchurch, New Zealand in 1992. He has worked as a Post-Doctoral Fellow at the Universities of Canterbury, New Zealand (1 year) and Toronto, Canada (2 years). At present, he is a staff member of the Facultad de Ingeniería Eléctrica, UMSNH, Morelia, Mexico. His research interests are in the dynamic and steady state analysis of power systems.

Roberto Tapia-Sánchez received his PhD from Ecole Centrale de Lille, Lille, France in 2011. He joined the Faculty of Electrical Engineering at the University of Michoacán, Morelia, Mexico in 2011, where he is currently professor in the Division of Graduate Studies. His research interest focuses on the design and control of renewable energy systems.

Olimpo Anaya-Lara (M'98) received the B.Eng. and M.Sc. degrees from the Instituto Tecnológico de Morelia, Morelia, Mexico, in 1990 and 1998, respectively, and the Ph.D. degree from the University of Glasgow, Glasgow, U.K., in 2003. His industrial experience includes periods with Nissan Mexicana, Toluca, Mexico, and Construcción y Servicios del Golfo (CSG) Consultants, Coatzacoalcos, Mexico. He is currently on secondment as a Det Norske Veritas Visiting Professor with the Norwegian Research Centre for Offshore Wind Technology, Trondheim, Norway, from his normal position as a Senior Lecturer with the Institute for Energy and Environment, Department of Electronic and Electrical Engineering, University of Strathclyde, Glasgow. His current research interests include wind generation, power electronics, and stability of mixed generation power systems.

Juan R. Rodríguez-Rodríguez (M'-) received the B.Eng. and Ph.D. degrees in electrical engineering from the Instituto Tecnológico de Morelia, Morelia, Mexico, in 2009 and 2015, respectively. He joined at National Autonomous University of Mexico (UNAM), Department of Electrical Energy, Mexico in 2017. His current research interests include power electronics converters, smart-grids, and power quality. 